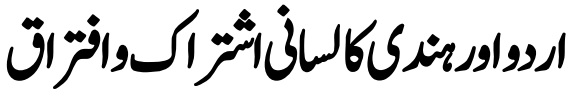

\section{Linguistic Similarity and Difference between Urdu and Hindi}

Saira Bano

Ph.D Research Scholar, Department of Urdu, National University of Modern Languages(NUML)

Islamabad, Pakistan

M. Faizan Adil

Research Scholar, Department of Urdu, National University of Modern Languages(NUML) Islamabad, Pakistan

\section{KEYWORDS}

Identity

Relationship

Separate

Thinkers

\section{A T E S}

\begin{tabular}{ll}
\hline Received & $25-07-2021$ \\
Accepted & $08-09-2021$ \\
Published & $19-09-2021$
\end{tabular}

\section{QR CODE}

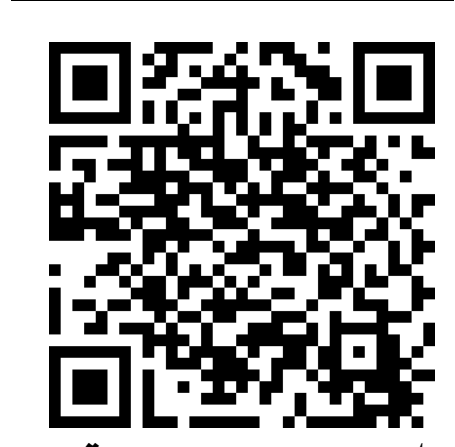

\begin{abstract}
A BSTRACT
Initially was only language used to express human ideas. In every age, along with customs and traditions, language also went through stages of evaluation. That is why language of each region is unique. This uniqueness of languages is of its identity. Like human beings, languages also have their own families, and different languages grow as sub-branches of language family. They flourish and sometimes thrive and come to life through process of evolution. When some languages die out. Urdu and Hindi also belong to large languages families. They have a deep relationship. And speaking of same relationship, some tinkers do not separate them from each other. When it sometimes thinkers, there is difference between in the two. At a glance, we will mention the linguistic similarities and difference between Urdu and Hindi. Where are places and where there is difference between them, but all of them are mentioned here.
\end{abstract}

DOI: https://doi.org/10.54064/negotiations.v1i2.17

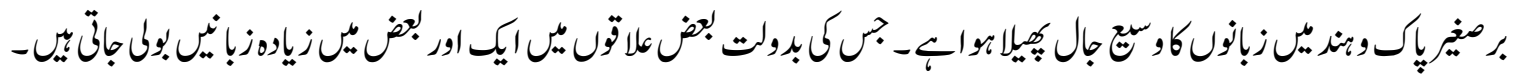

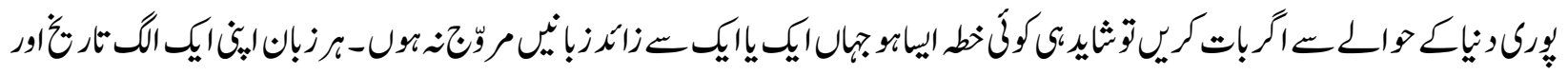

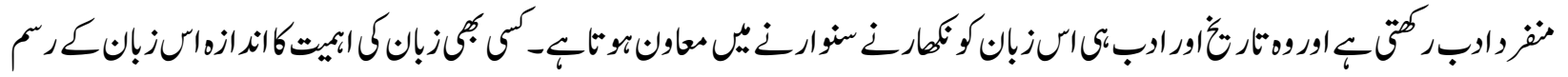

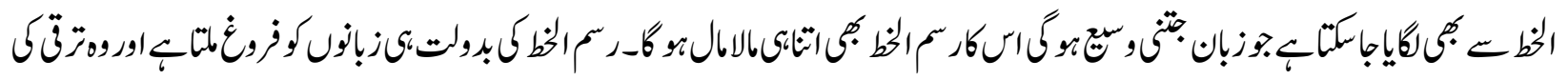

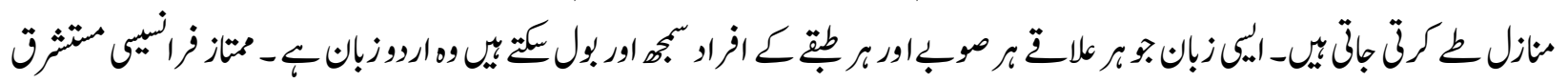




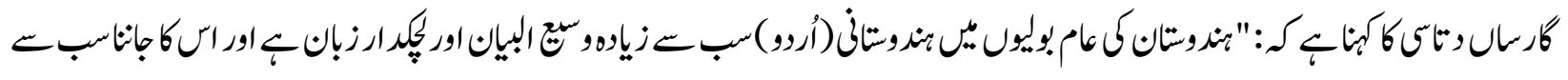

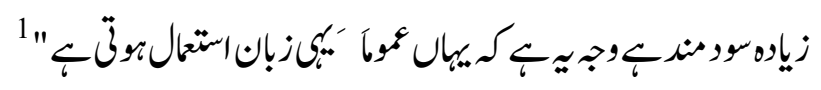

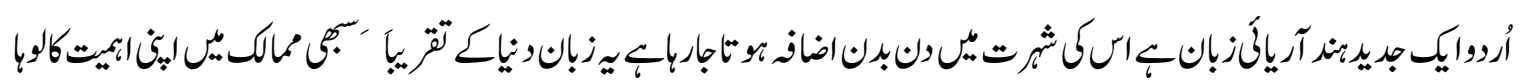

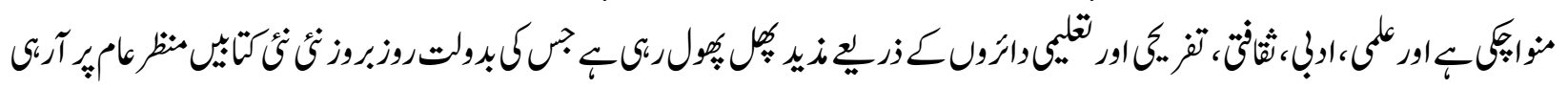

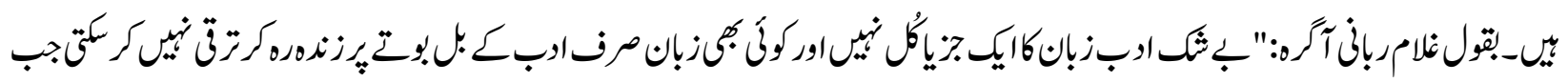

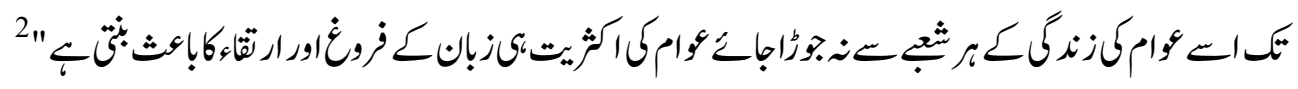

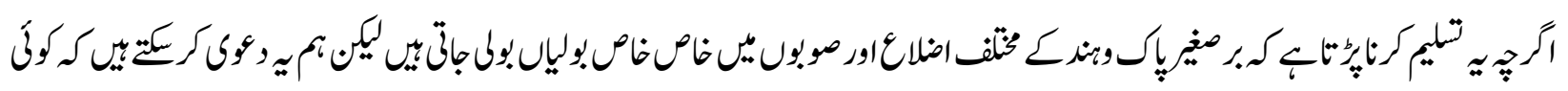

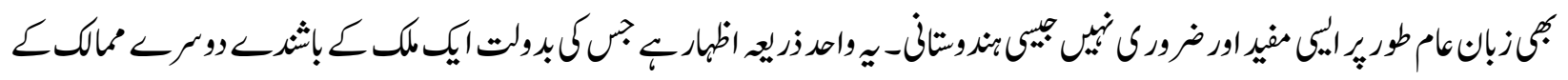

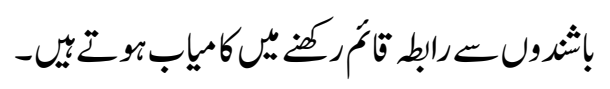

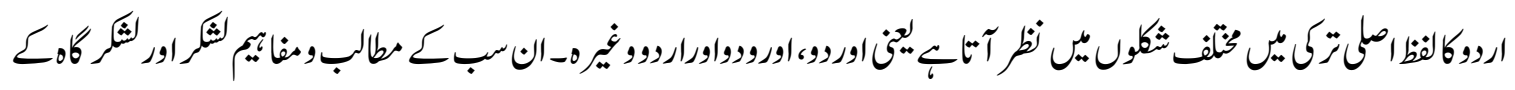

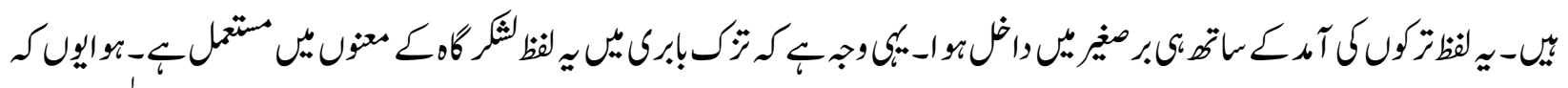

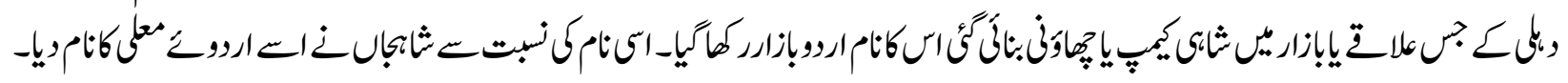

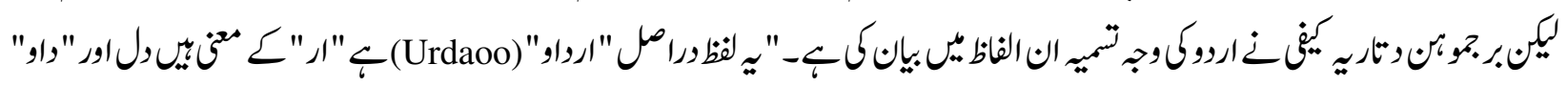

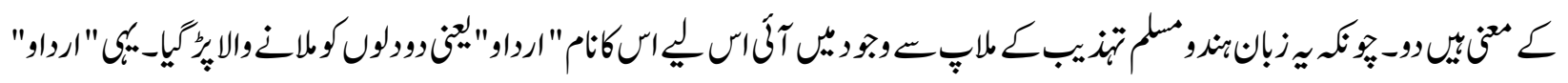
بعركوارو.كن تيا"

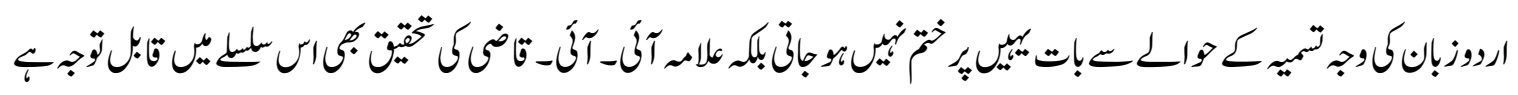

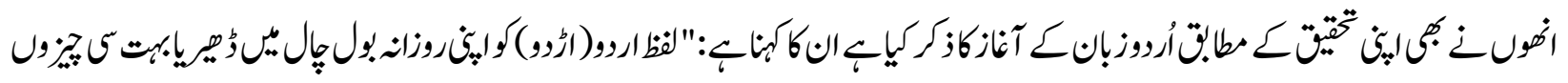

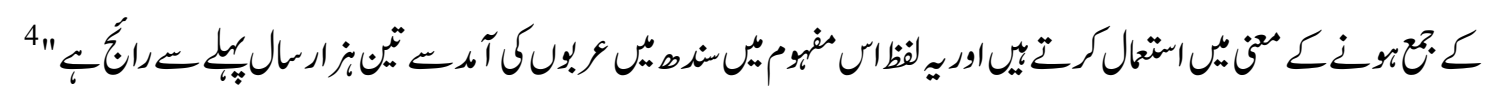

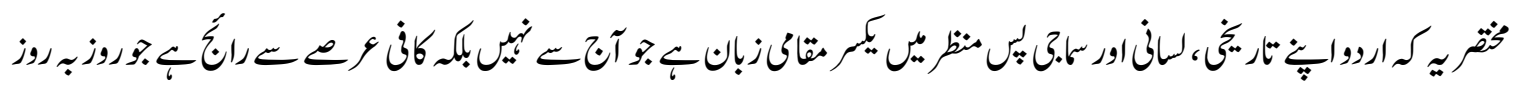

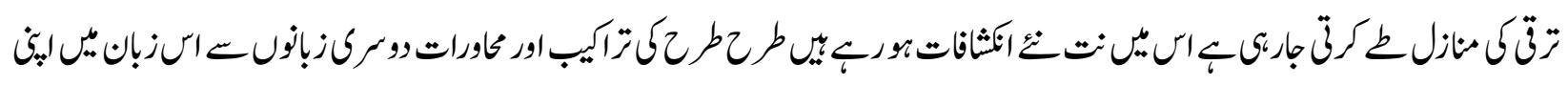

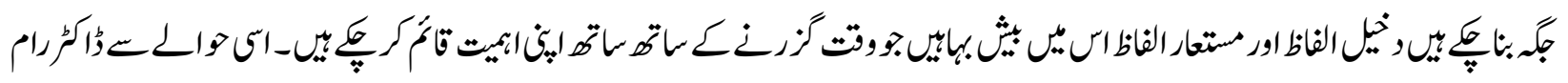

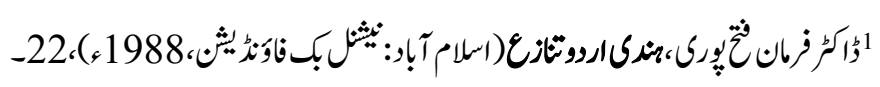

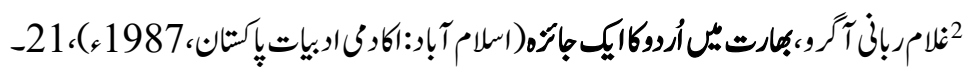

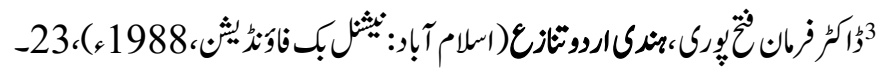




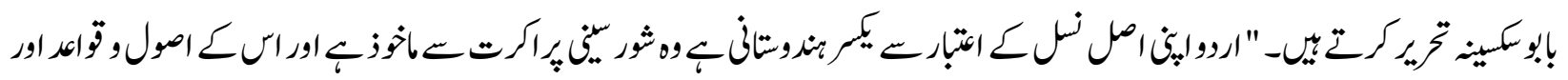

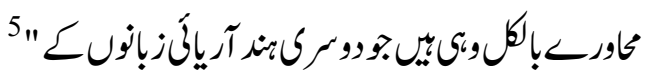

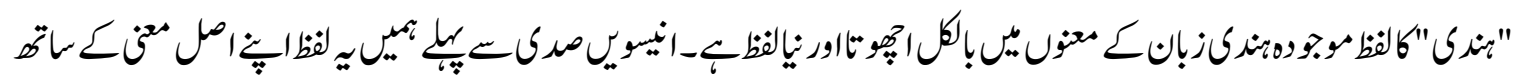

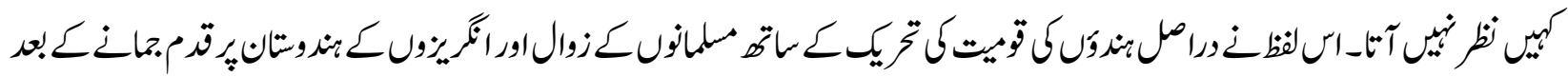

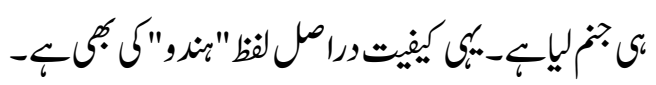

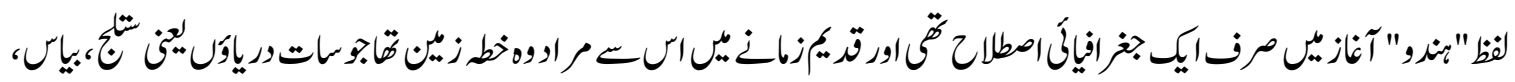

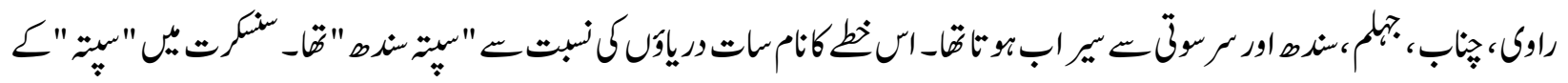

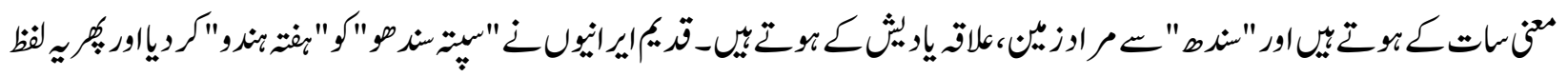

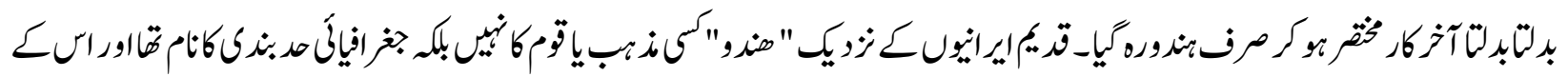

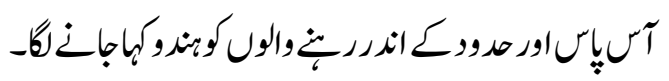

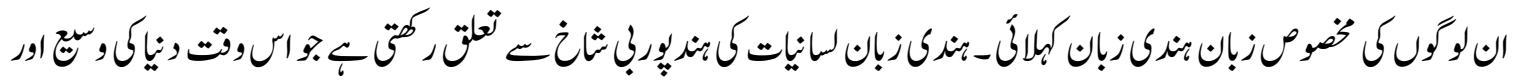

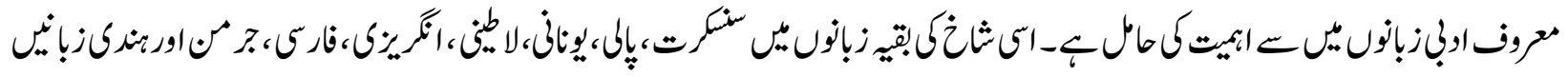

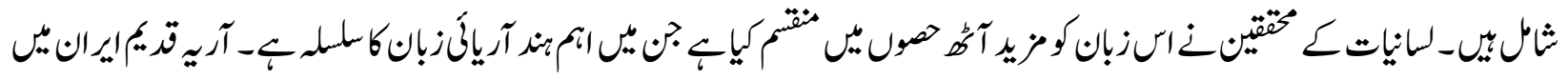

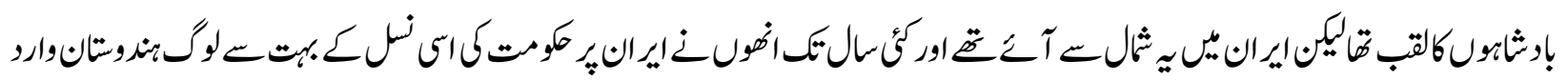

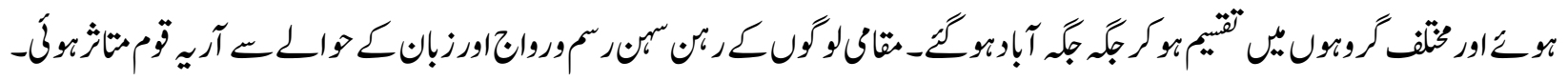

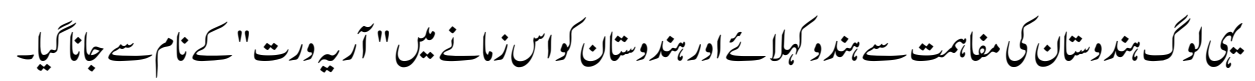

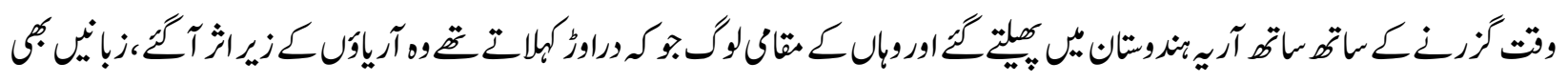

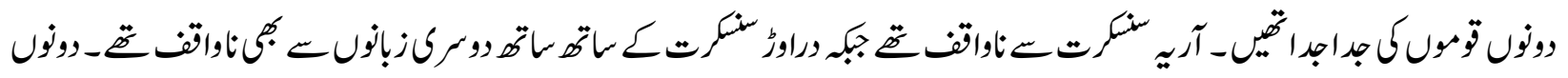

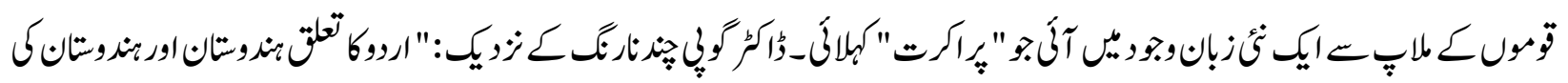

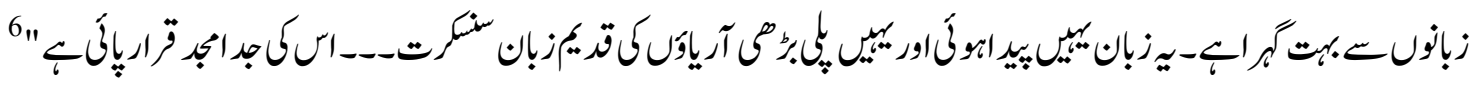

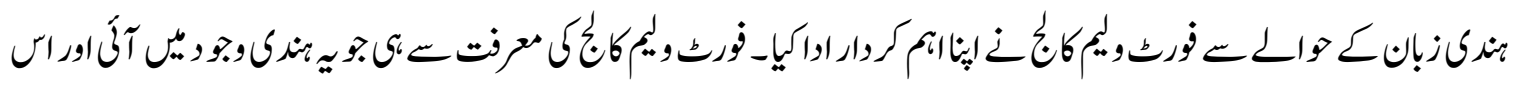

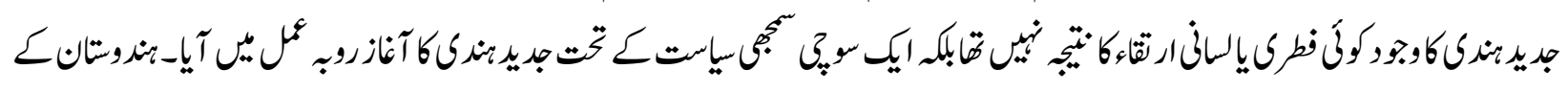

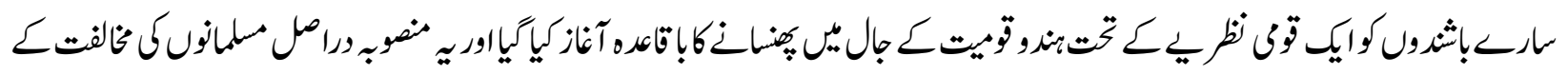

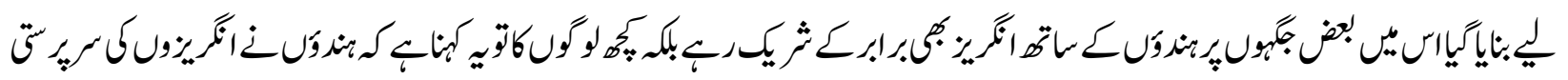




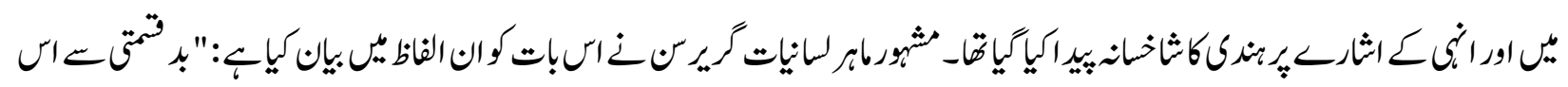

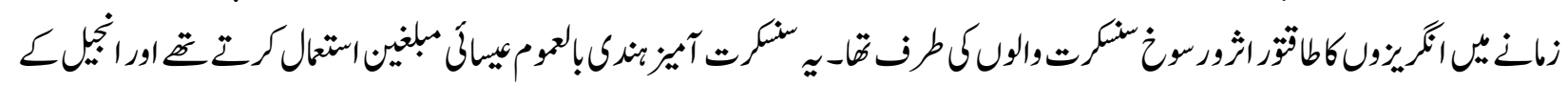

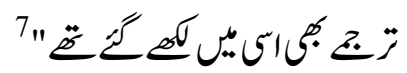

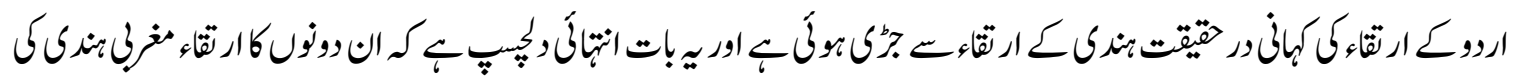

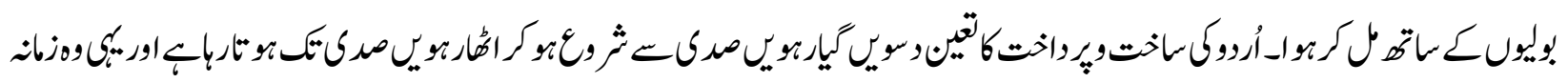

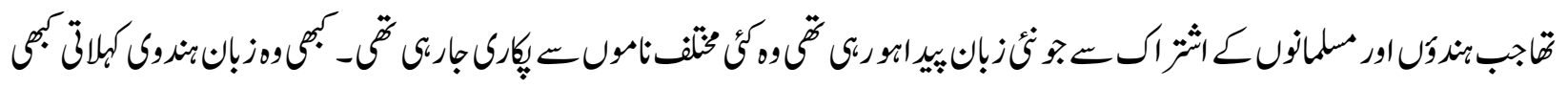

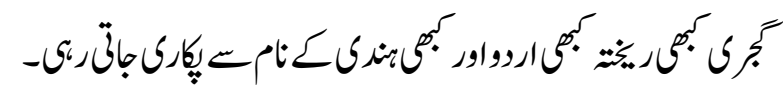

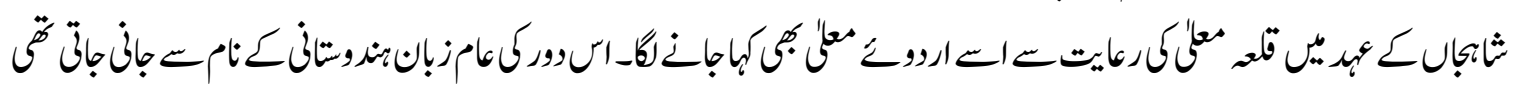

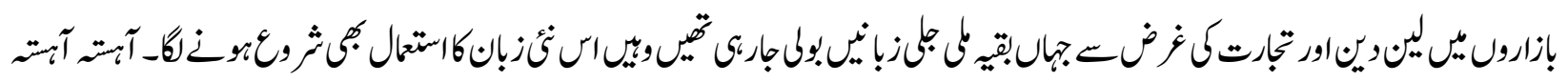

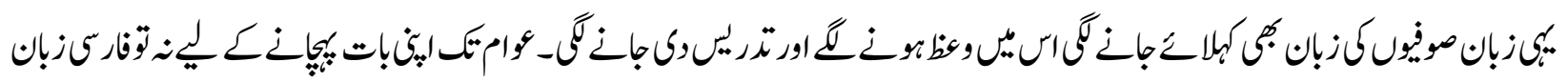

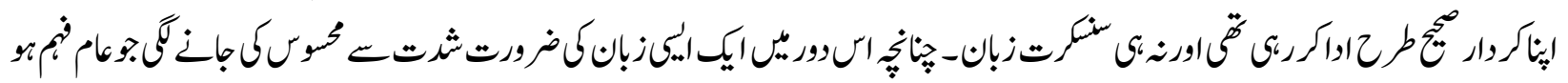

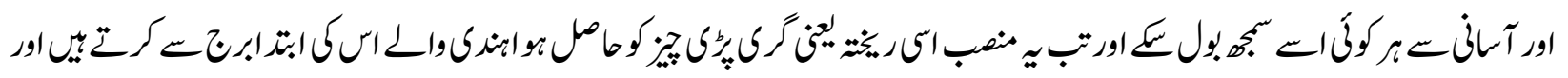

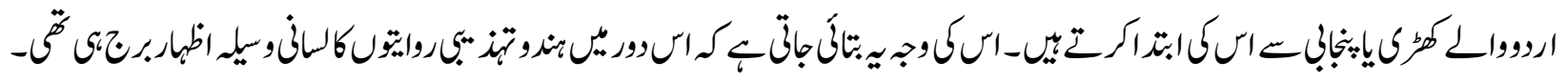

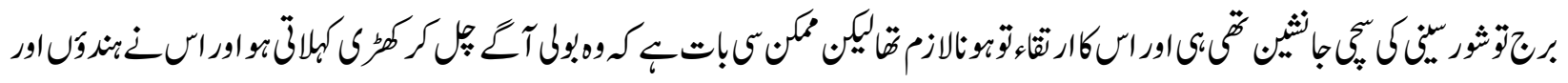

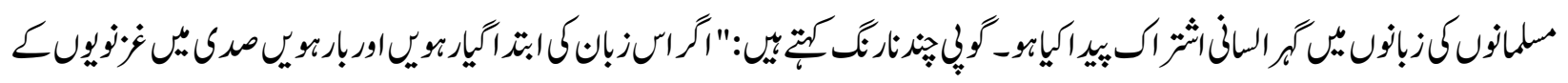

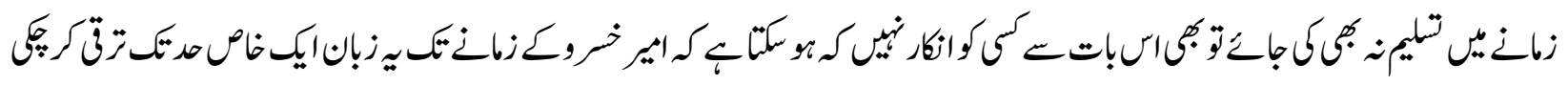

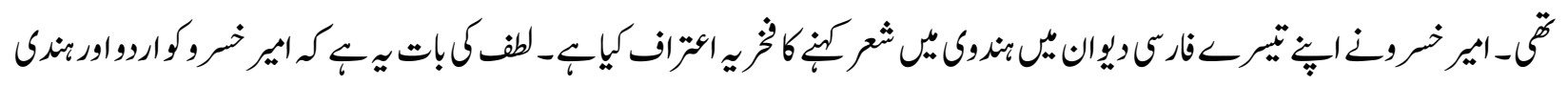

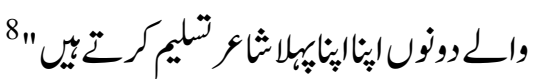

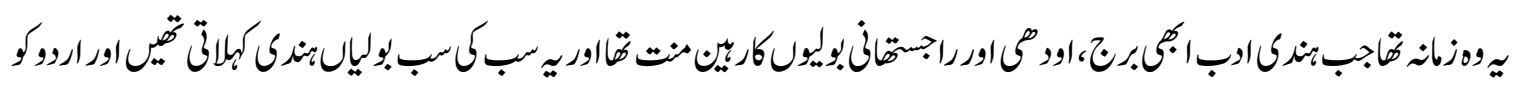

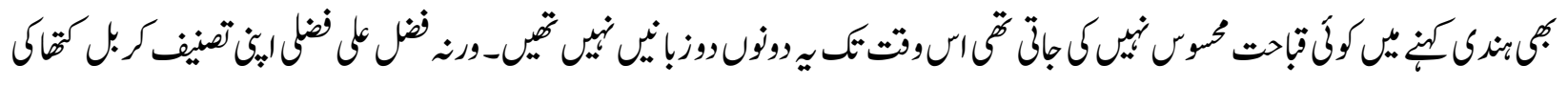

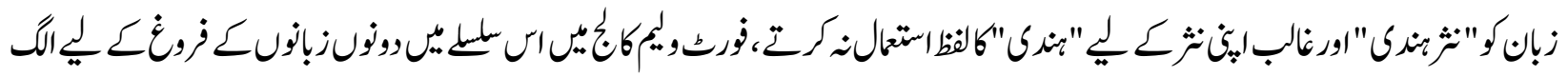

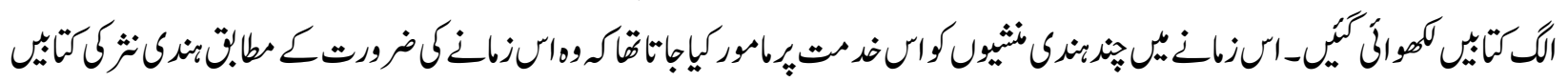

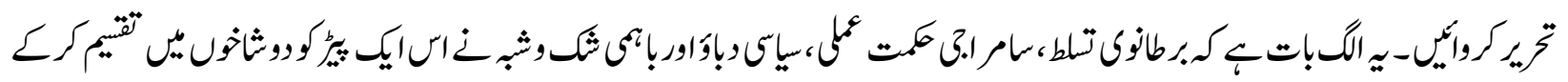

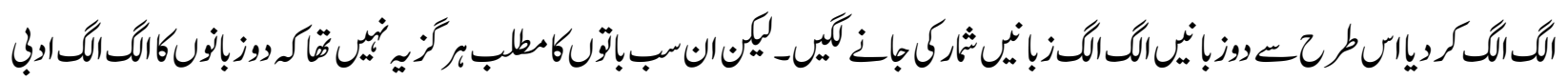

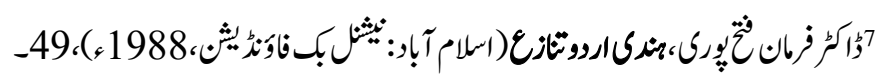

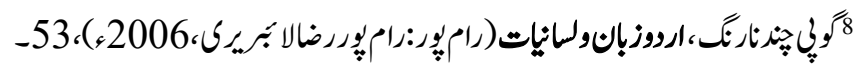




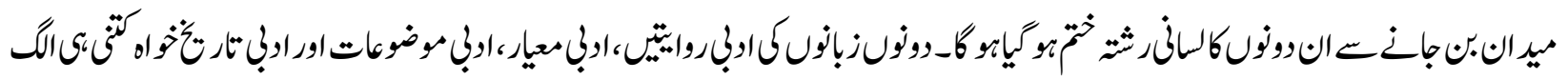

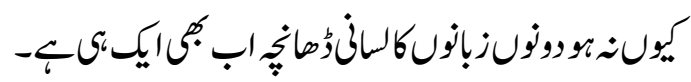

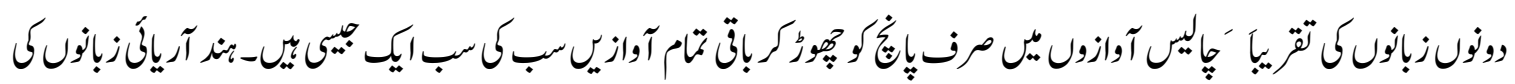

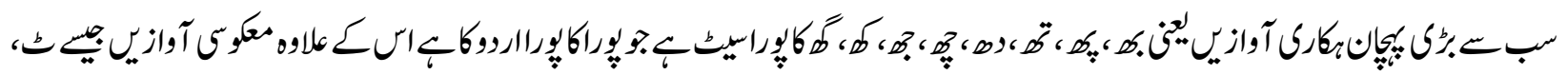

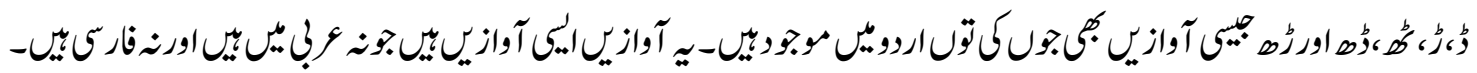

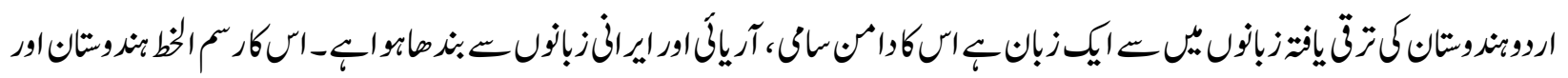

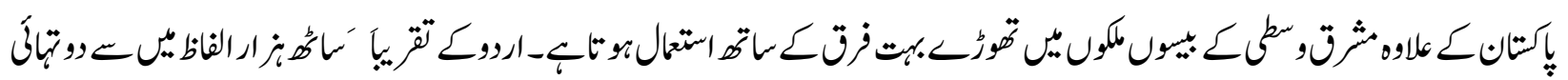

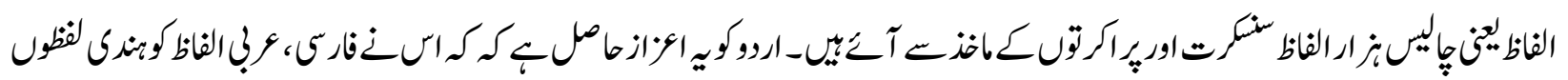

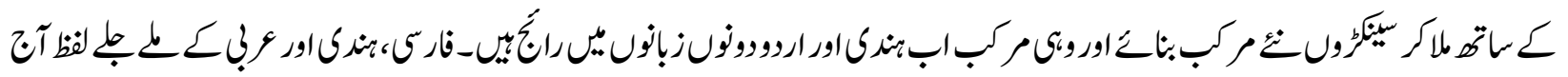

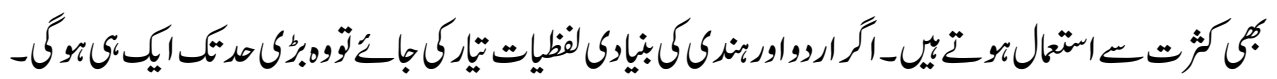

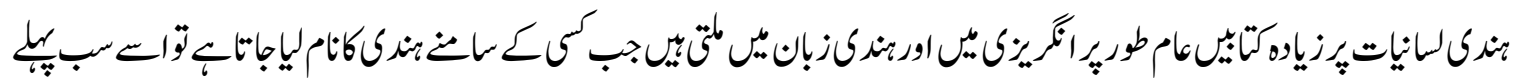

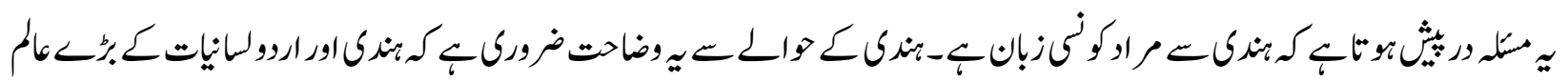

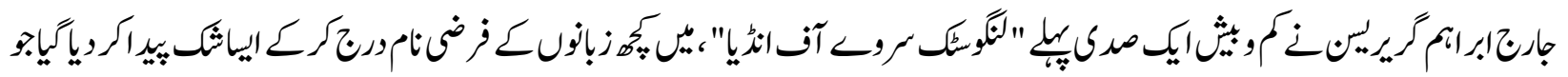

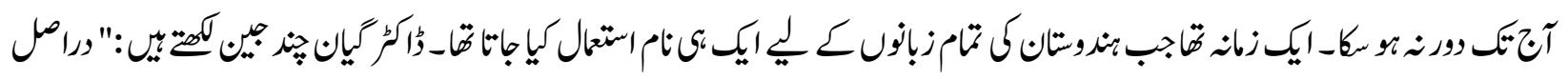

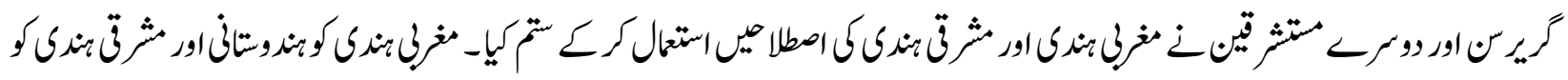

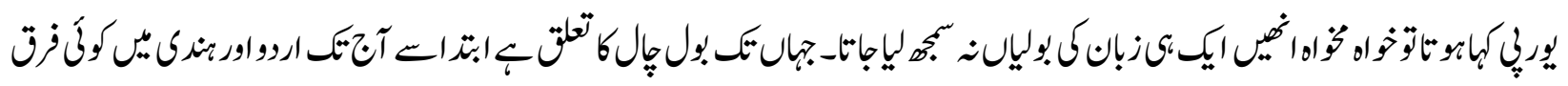
$9 "$

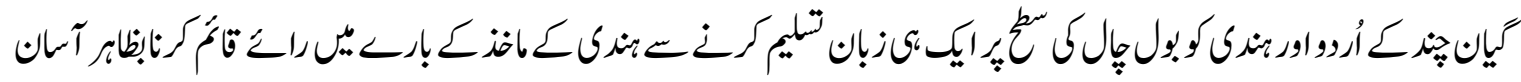

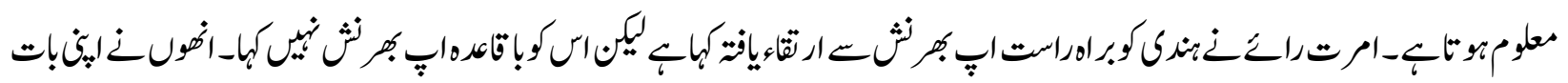

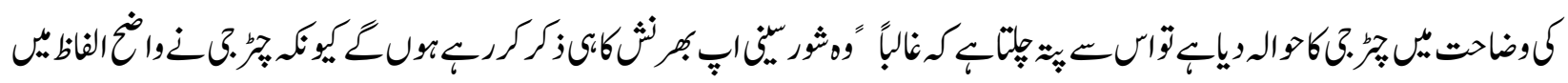

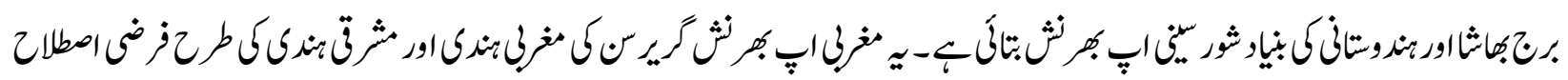

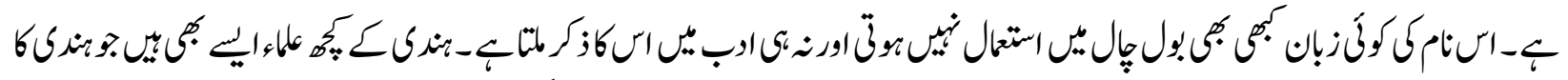

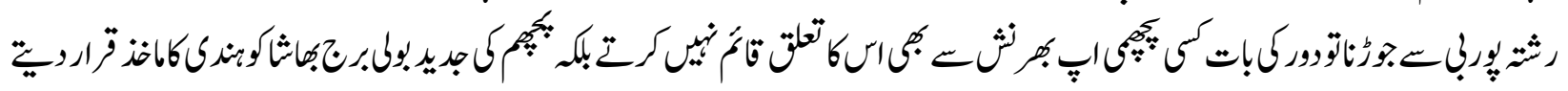

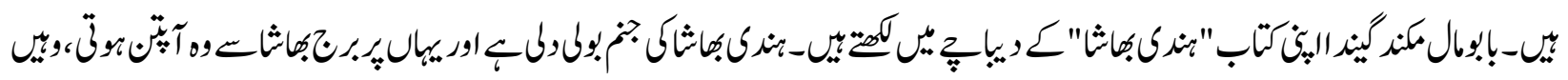

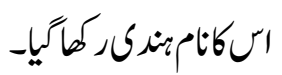




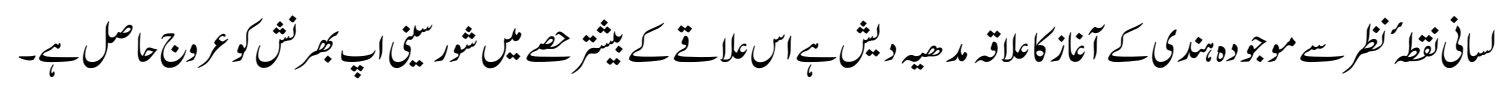

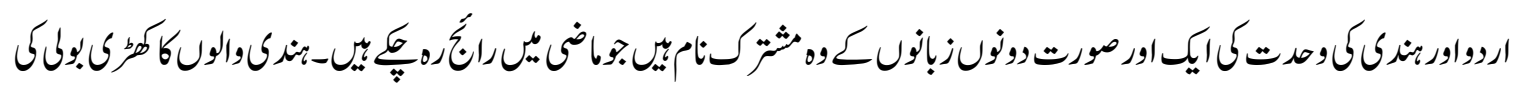

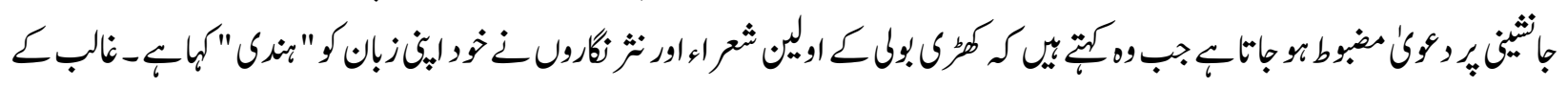

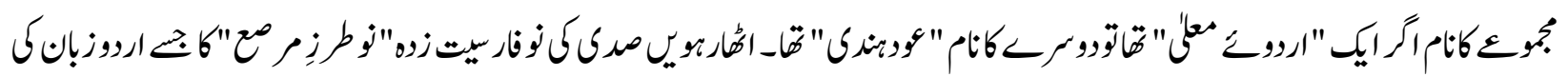

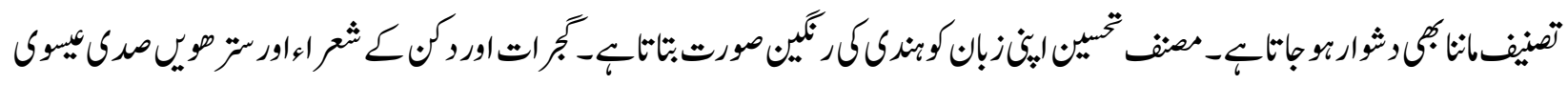

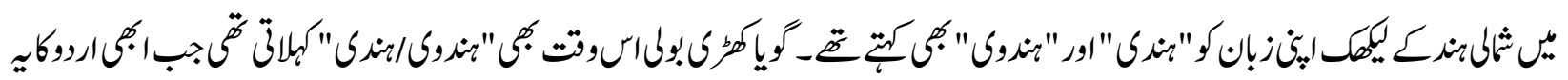

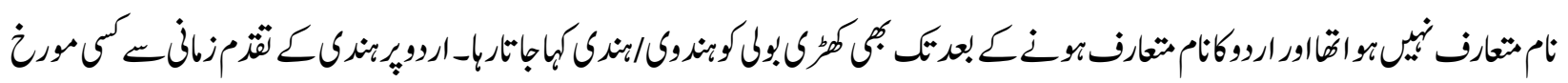

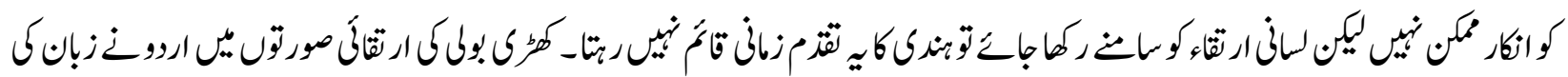

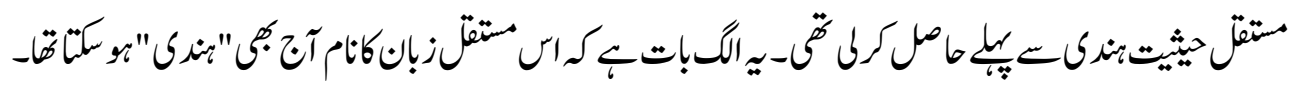

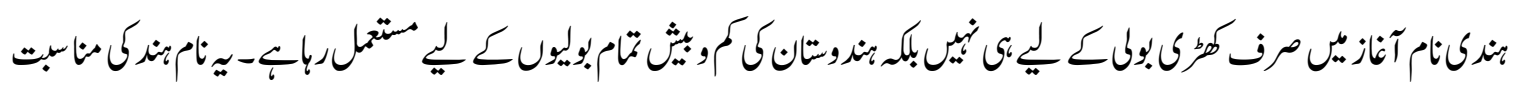

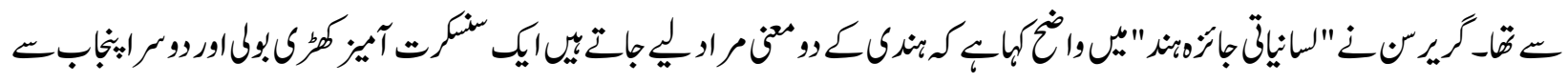

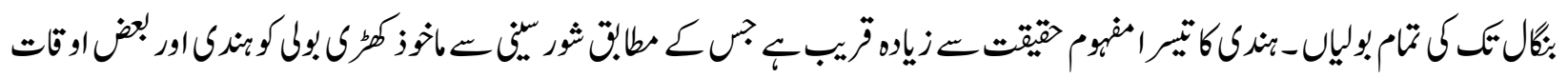

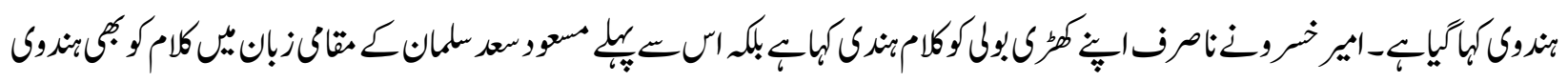

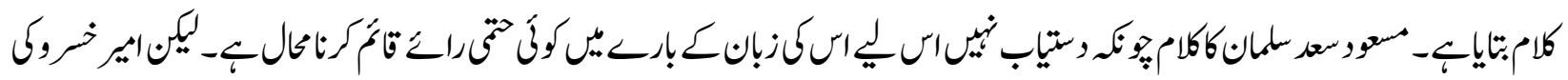

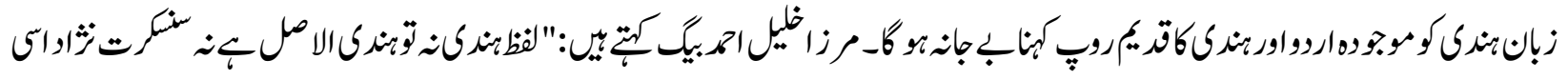

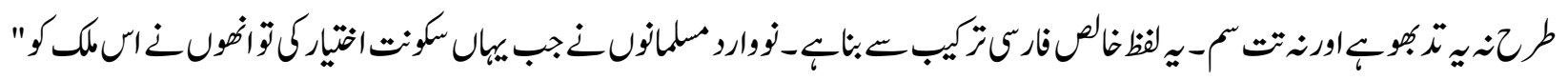

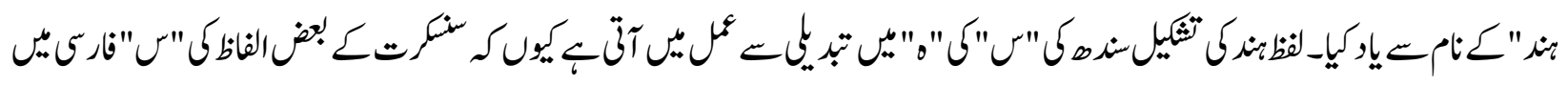

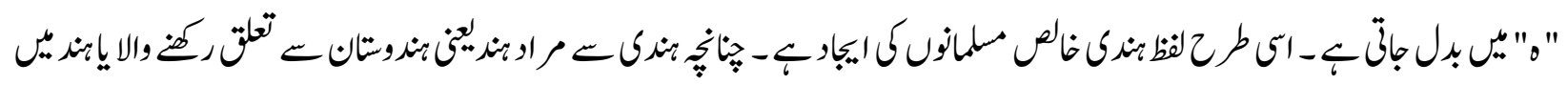

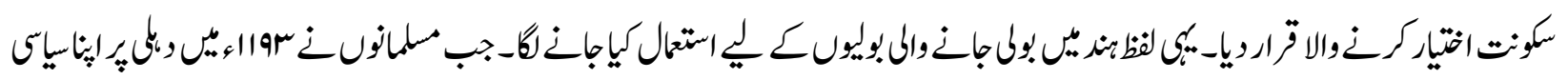

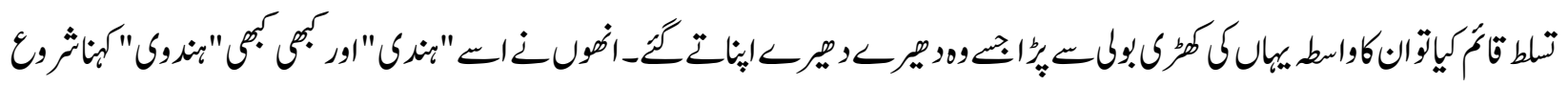

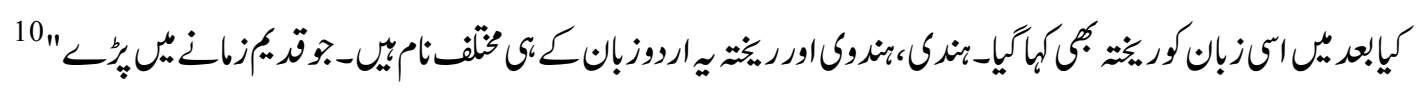

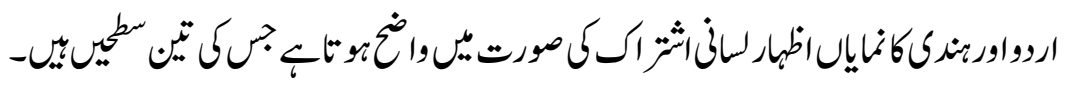

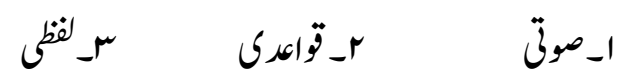




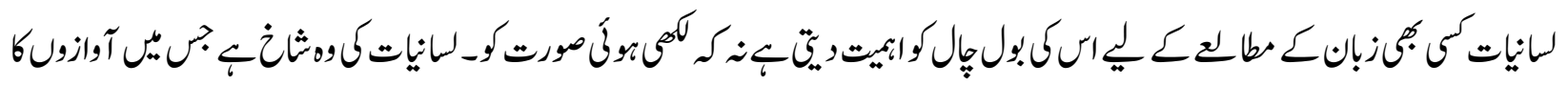

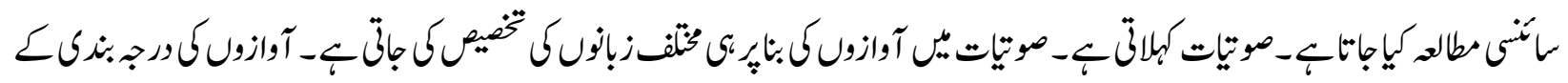

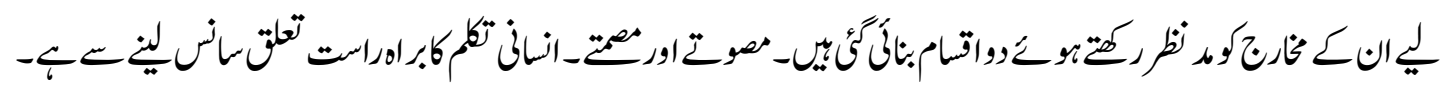

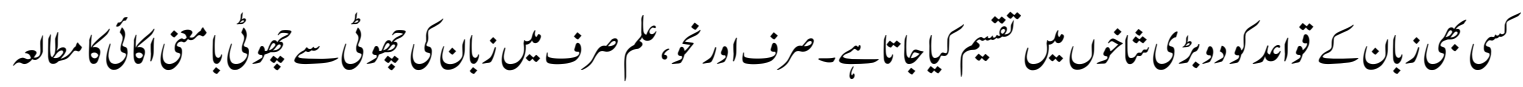

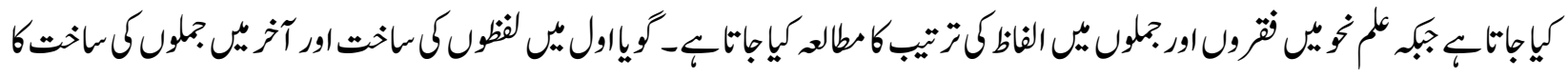
مطالد

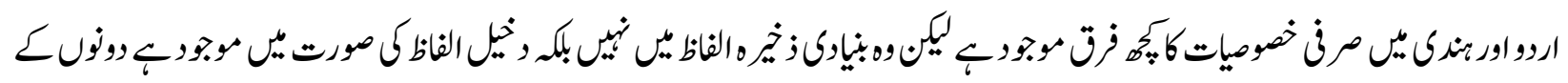

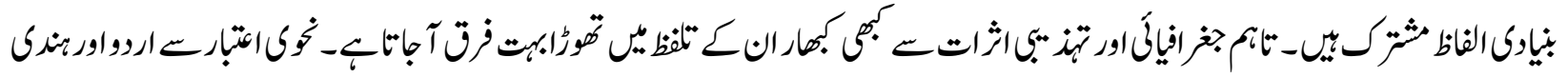

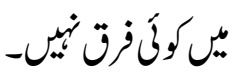

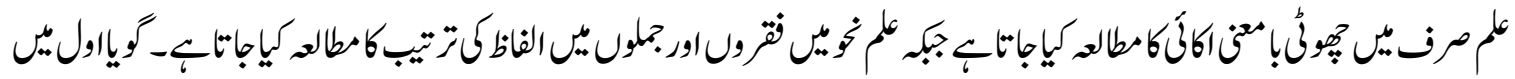

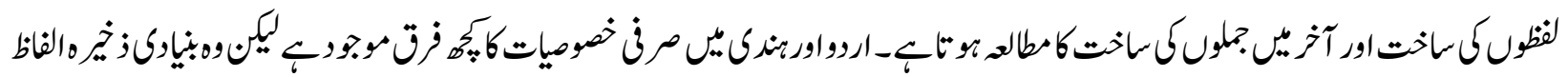

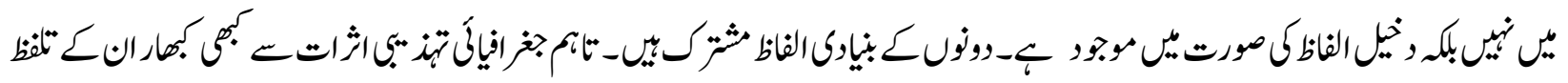

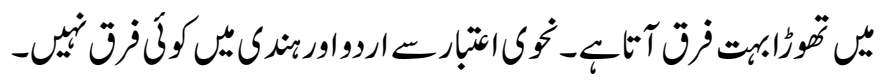

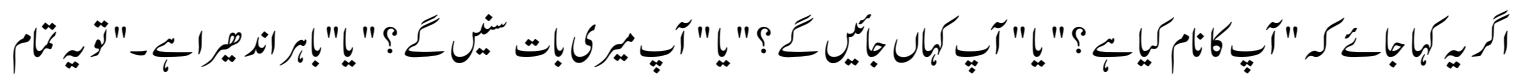

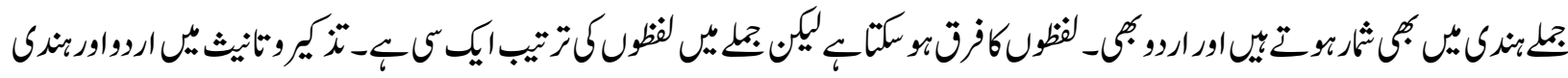

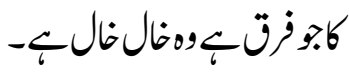

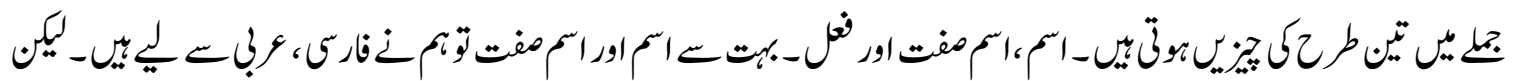

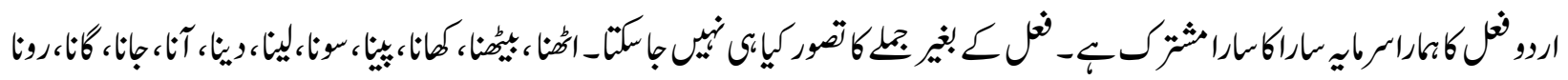

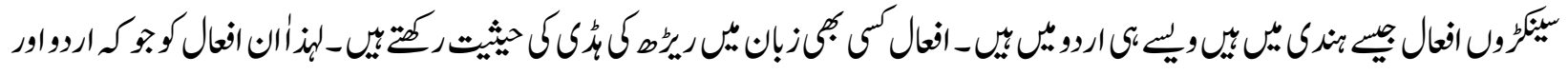

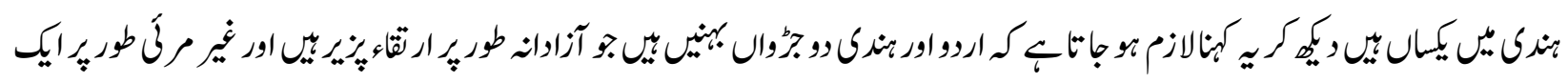

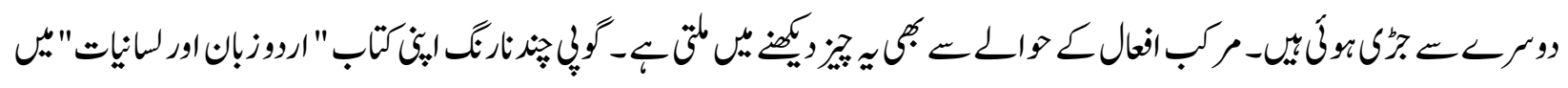

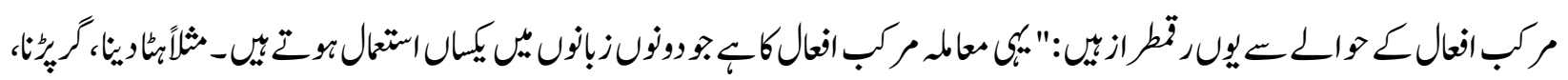

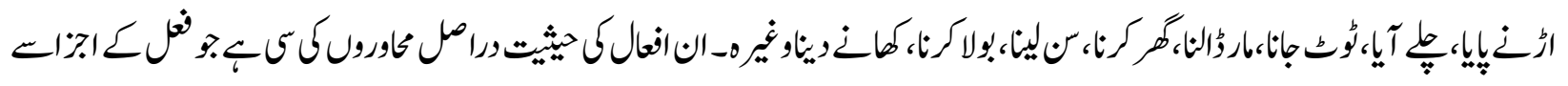

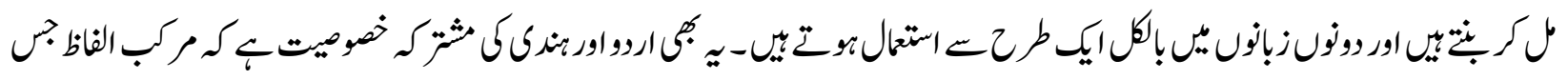
كثت 11 


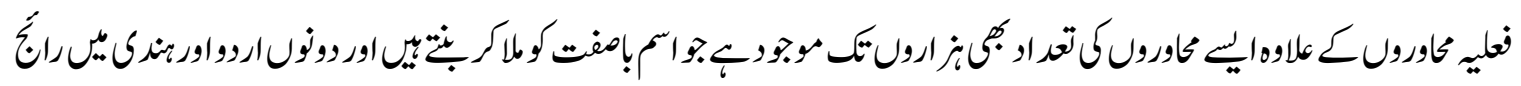

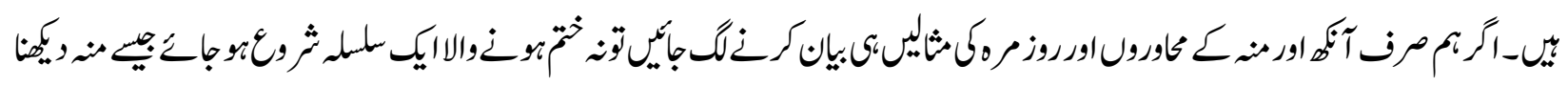

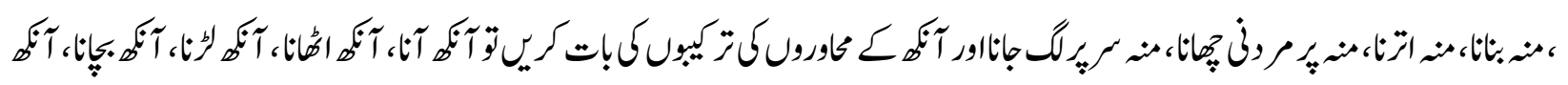

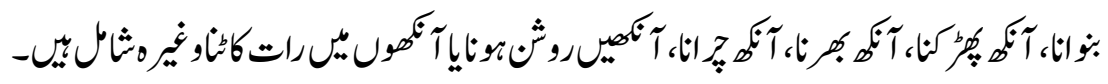

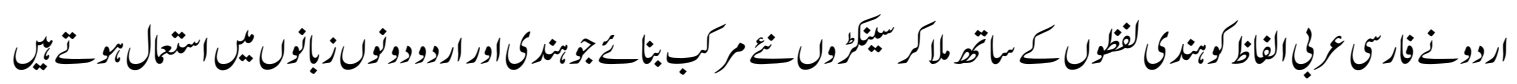

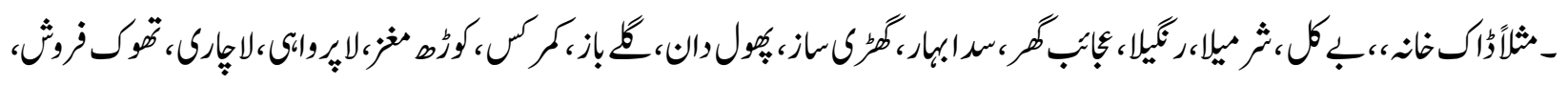

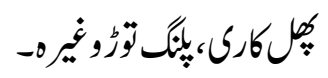

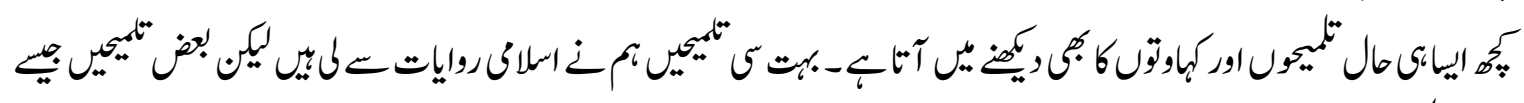

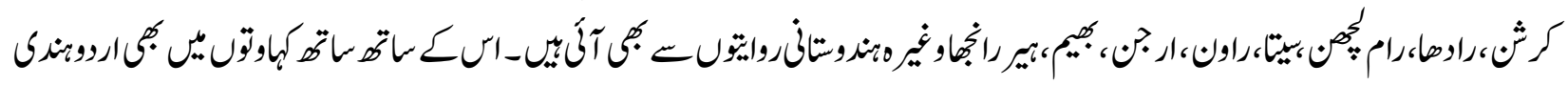

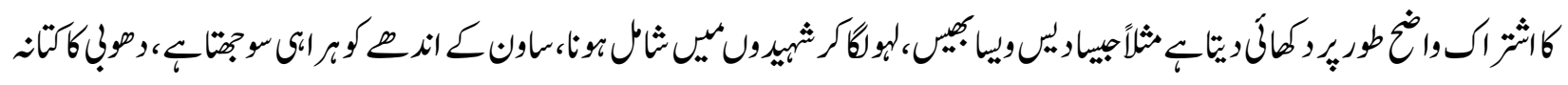

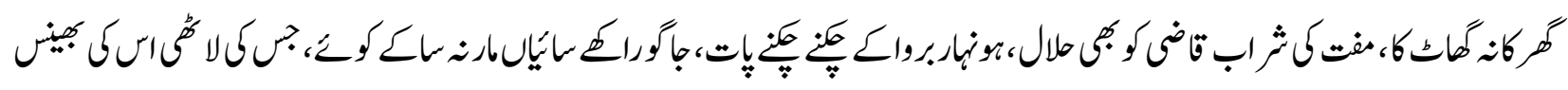

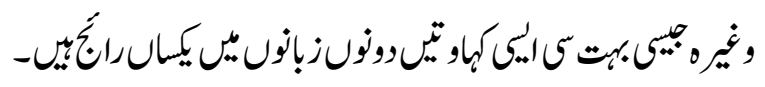

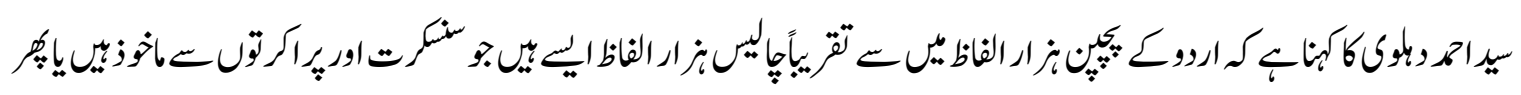

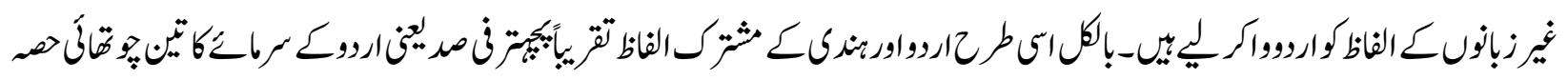

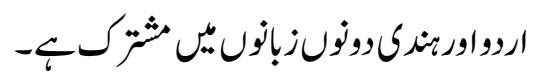

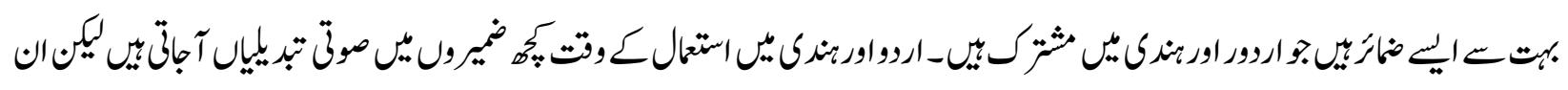

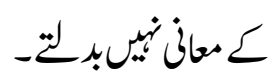

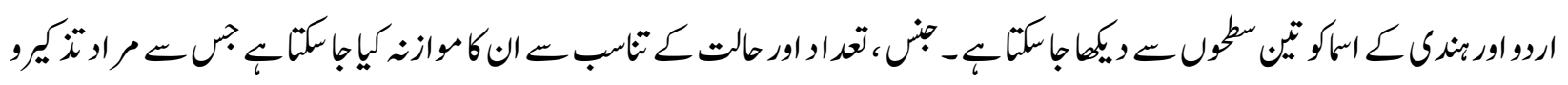

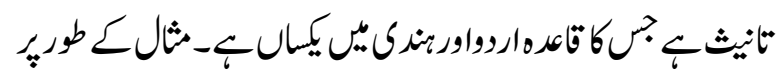

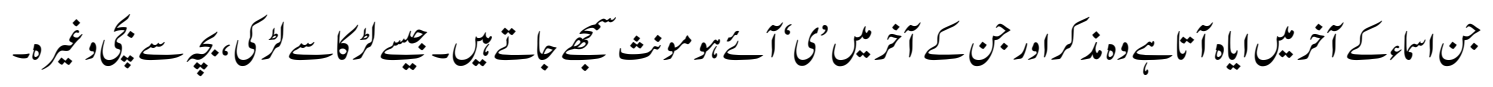

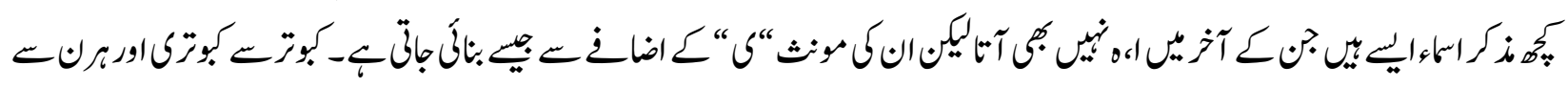

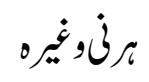

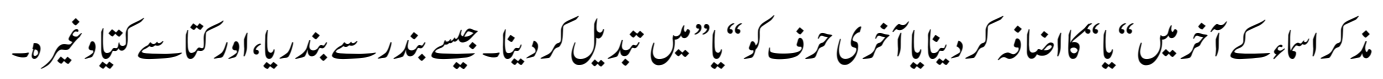

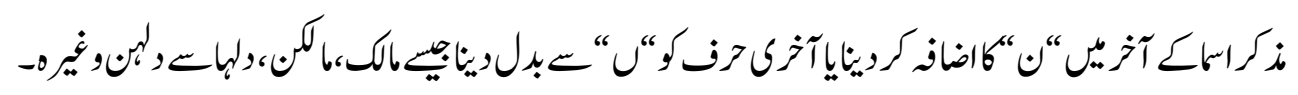

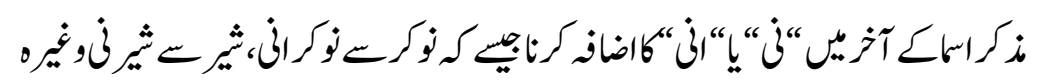




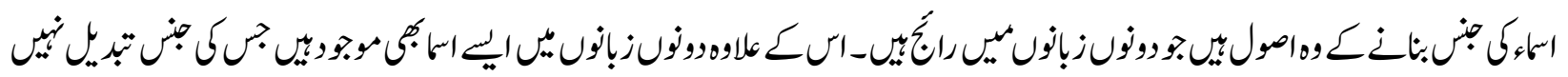

$$
\begin{aligned}
& \text { موتجبياك، }
\end{aligned}
$$

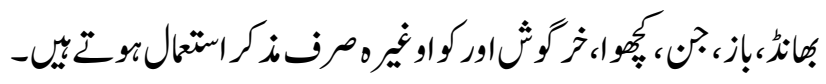

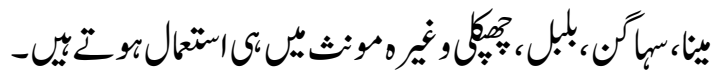

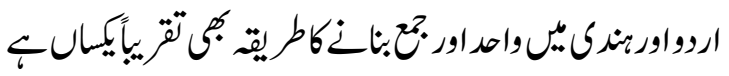

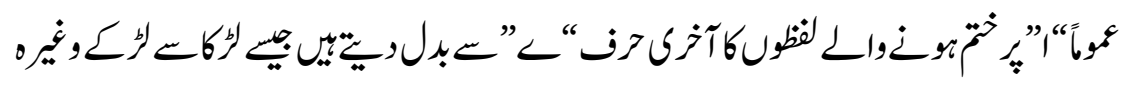

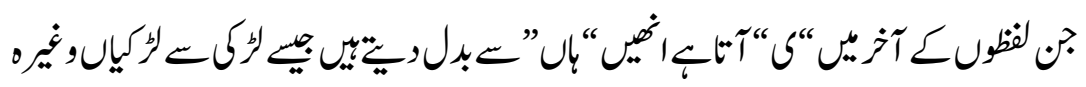

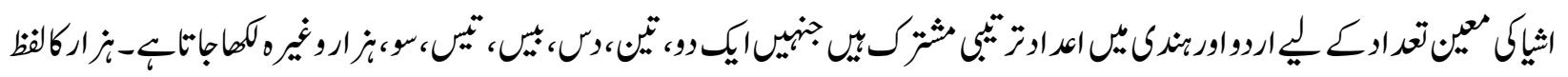

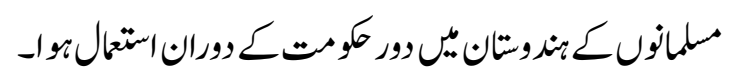

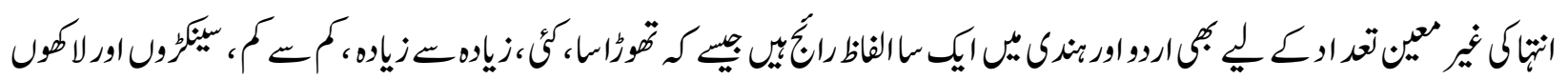
,

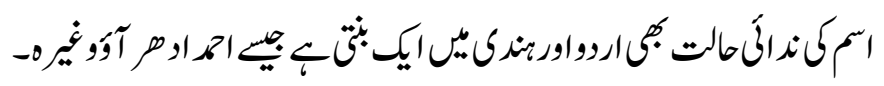

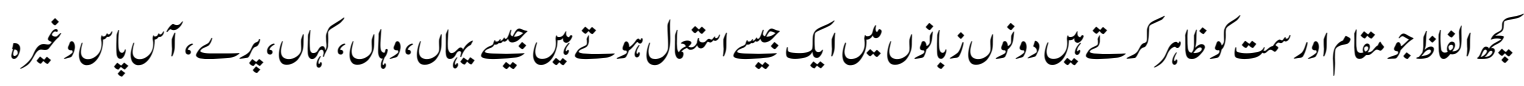

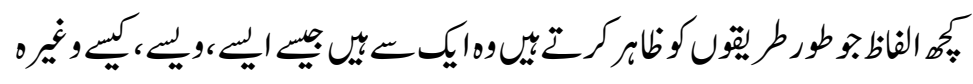

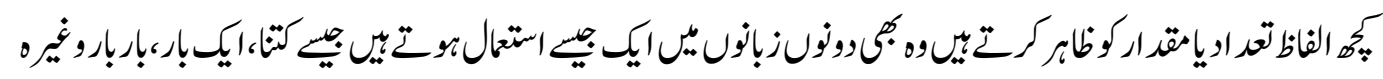

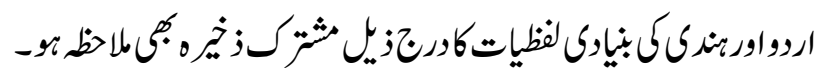

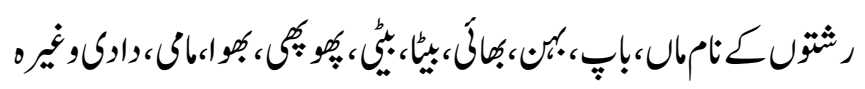

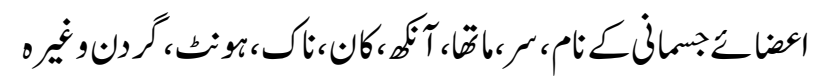

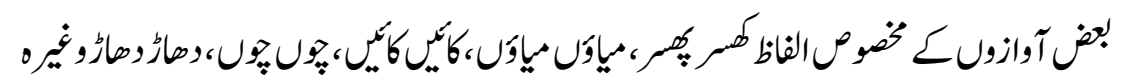

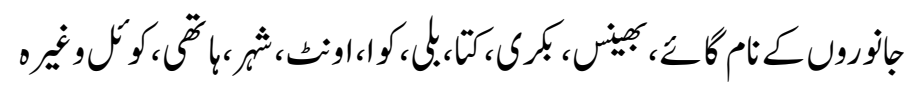

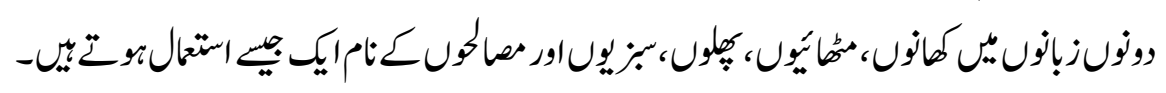

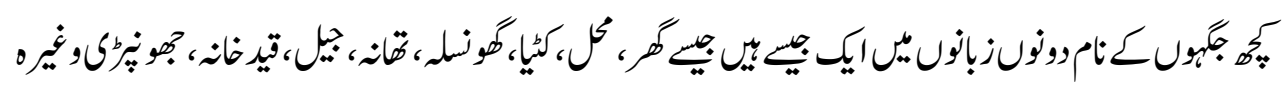

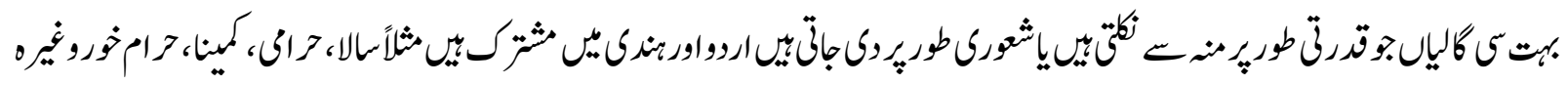

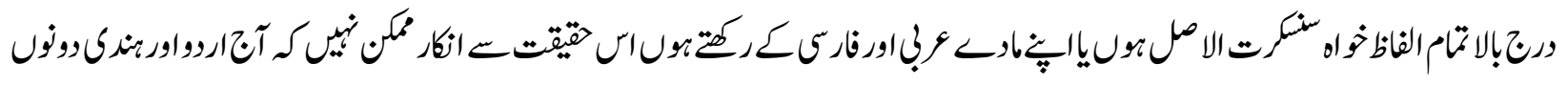

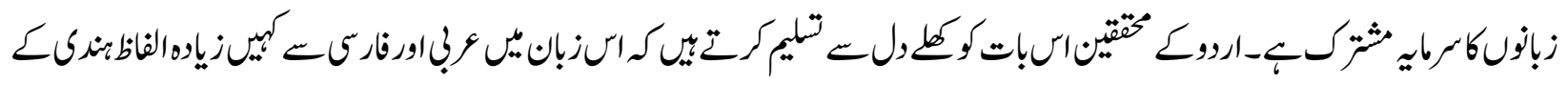

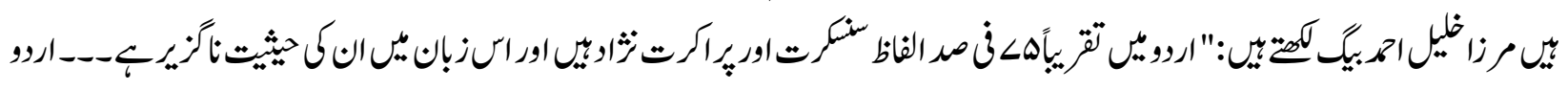




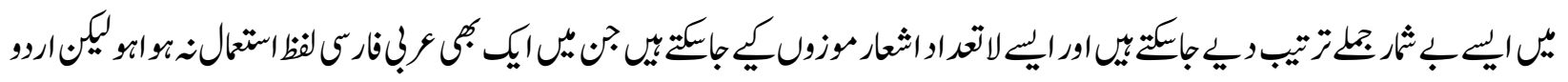

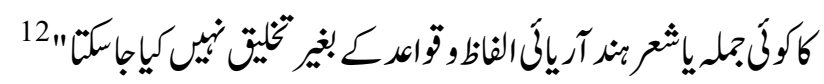

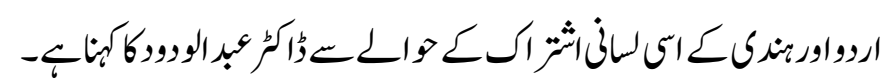

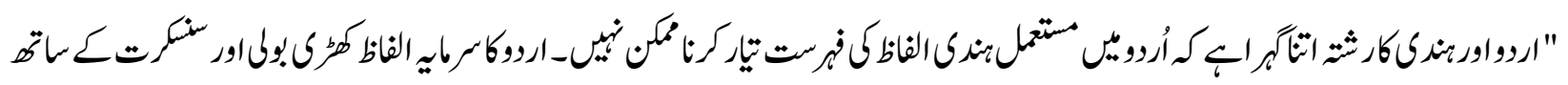

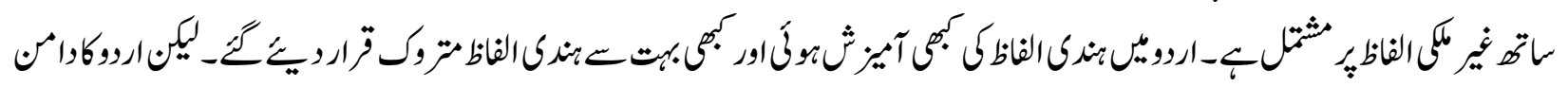
13 "

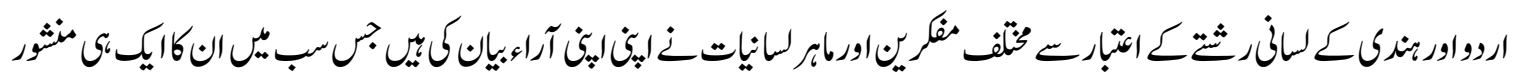

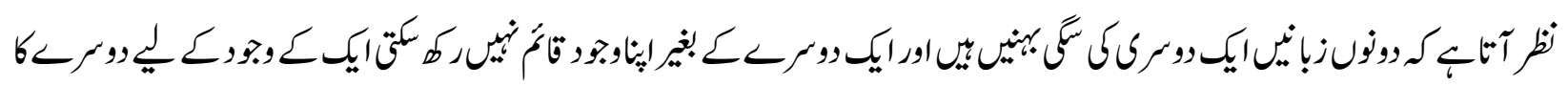

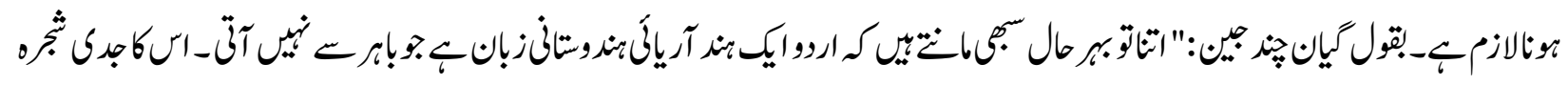

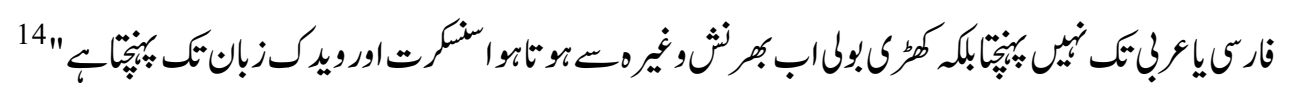

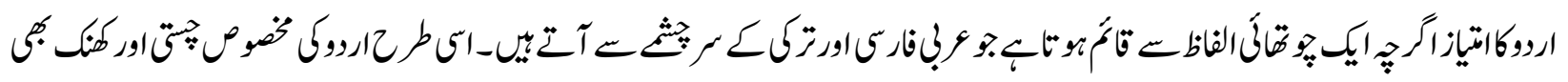

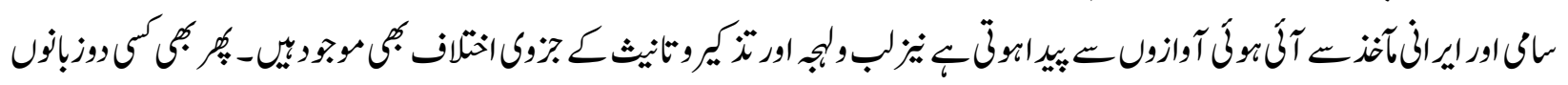

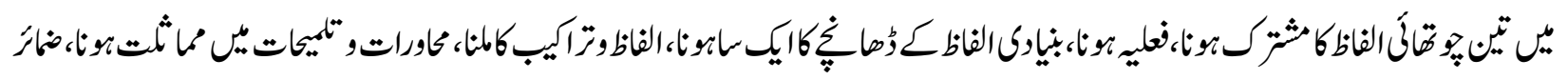

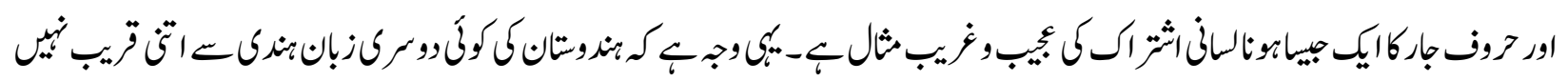

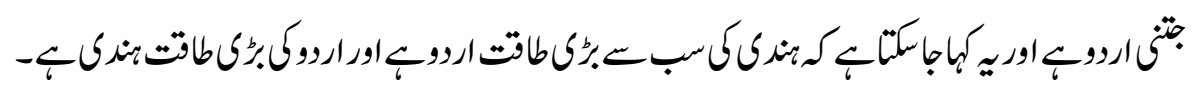
论社拧

$$
\begin{aligned}
& \text { 12 }
\end{aligned}
$$

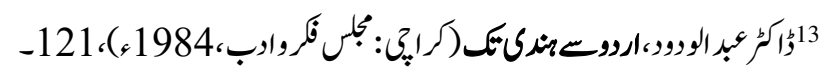

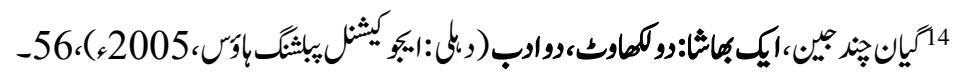

